\title{
Oxygen-Induced and pH-Induced Direct Current Artifacts on Invasive Platinum/Iridium Electrodes for Electrocorticography
}

\author{
Sebastian Major ${ }^{1,2,3}$, Nenad Gajovic-Eichelmann ${ }^{4}$, Johannes Woitzik ${ }^{5}$ and Jens P. Dreier ${ }^{1,2,3,6,7^{*}}$ (0) \\ (C) 2021 The Author(s)
}

\begin{abstract}
Background: Spreading depolarization (SD) and the initial, still reversible phase of neuronal cytotoxic edema in the cerebral gray matter are two modalities of the same process. SD may thus serve as a real-time mechanistic biomarker for impending parenchyma damage in patients during neurocritical care. Using subdural platinum/iridium (Pt/lr) electrodes, SD is observed as a large negative direct current (DC) shift. Besides SD, there are other causes of DC shifts that are not to be confused with SD. Here, we systematically analyzed DC artifacts in ventilated patients by observing changes in the fraction of inspired oxygen. For the same change in blood oxygenation, we found that negative and positive DC shifts can simultaneously occur at adjacent Pt/Ir electrodes.
\end{abstract}

Methods: Nurses and intensivists typically increase blood oxygenation by increasing the fraction of inspired oxygen at the ventilator before performing manipulations on the patient. We retrospectively identified 20 such episodes in six patients via tissue partial pressure of oxygen $\left(\mathrm{p}_{\mathrm{ti}} \mathrm{O}_{2}\right)$ measurements with an intracortical $\mathrm{O}_{2}$ sensor and analyzed the associated DC shifts. In vitro, we compared Pt/lr with silver/silver chloride (Ag/AgCl) to assess DC responses to changes in $\mathrm{pO}_{2}, \mathrm{pH}$, or 5 -min square voltage pulses and investigated the effect of electrode polarization on $\mathrm{pO}_{2}$-induced DC artifacts.

Results: Hyperoxygenation episodes started from a $\mathrm{p}_{\mathrm{ti}} \mathrm{O}_{2}$ of $37(30-40) \mathrm{mmHg}$ (median and interquartile range) reaching 71 (50-97) $\mathrm{mmHg}$. During a total of 20 episodes on each of six subdural Pt/lr electrodes in six patients, we observed 95 predominantly negative responses in six patients, 25 predominantly positive responses in four patients, and no brain activity changes. Adjacent electrodes could show positive and negative responses simultaneously. In vitro, $\mathrm{Pt} / \mathrm{Ir}$ in contrast with $\mathrm{Ag} / \mathrm{AgCl}$ responded to changes in either $\mathrm{pO}_{2}$ or $\mathrm{pH}$ with large $\mathrm{DC}$ shifts. In response to square voltage pulses, Pt/Ir falsely showed smaller DC shifts than Ag/AgCl, with the worst performance under anoxia. In response to $\mathrm{PO}_{2}$ increase, $\mathrm{Pt} / \mathrm{Ir}$ showed $\mathrm{DC}$ positivity when positively polarized and $\mathrm{DC}$ negativity when negatively polarized.

Conclusions: The magnitude of $\mathrm{pO}_{2}$-induced subdural DC shifts by approximately $6 \mathrm{mV}$ was similar to that of SDs, but they did not show a sequential onset at adjacent recording sites, could be either predominantly negative or positive in contrast with the always negative $\mathrm{DC}$ shifts of SD, and were not accompanied by brain activity depression.

\footnotetext{
*Correspondence: jens.dreier@charite.de

${ }^{1}$ Center for Stroke Research Berlin, Campus Charité Mitte, Charité-

Universitätsmedizin Berlin, corporate member of Freie Universität Berlin,

Humboldt-Universität zu Berlin, and Berlin Institute of Health, Charitéplatz

1, 10117 Berlin, Germany

Full list of author information is available at the end of the article
}

This article is part of the collection "Spreading Cortical Depolarization". 
Opposing polarities of $\mathrm{pO}_{2}$-induced DC artifacts may result from differences in baseline electrode polarization or subdural $p_{\mathrm{ti}} \mathrm{O}_{2}$ inhomogeneities relative to subdermal $\mathrm{p}_{\mathrm{ti}} \mathrm{O}_{2}$ at the quasi-reference.

Keywords: Multimodal monitoring, Cytotoxic edema, Spreading depolarization, Electrocorticography, Aneurysmal subarachnoid hemorrhage, Traumatic brain injury, Platinum electrode

\section{Introduction}

Spreading depolarization (SD) and the initial, still reversible phase of neuronal cytotoxic edema in the cerebral gray matter are two modalities of the same process [1]. The term SD describes the electrophysiological aspect, and the term cytotoxic edema describes the pathomorphological aspect of this process. Accordingly, SD is observed as a large negative direct current (DC) shift, two-photon microscopy shows neuronal swelling with a beaded morphology of neuronal dendrites during SD [2], and magnetic resonance imaging shows a propagating wave of diffusion restriction [3-5]. SDs occur during a plethora of clinical conditions, including migraine aura $[6,7]$, ischemic stroke $[8,9]$, traumatic brain injury $[10$, $11]$, aneurysmal subarachnoid hemorrhage (aSAH) and delayed ischemic stroke [12-14], spontaneous intracerebral hemorrhage [15], subdural hematoma [16], development of brain death $[17,18]$, and dying from circulatory arrest [19]. The SD continuum describes the spectrum from transient events of intermediate duration to short duration in less ischemic or adequately supplied tissue to terminal SDs in severely ischemic tissue characterized by the transition of the neurons from the state of injury to cell death $[20,21]$. Dying is characterized by the transition from this negative DC shift to the so-called negative ultraslow potential in electrophysiology and continued diffusion restriction in diffusion-weighted magnetic resonance imaging $[12,17,18,22-24]$. Thus, terminal SD is composed of the initial SD phase followed by the SD-initiated negative ultraslow potential phase [12].

In addition to the assessment of SD and neuronal cytotoxic edema, electrocorticography (ECoG) also allows the assessment of spontaneous brain activity in the neural network. Spontaneous brain activity results from the firing of neurons. The firing of upstream neurons leads to postsynaptic potentials in downstream neurons. These cause rapid extracellular field potential changes that can be recorded in the alternating current (AC) frequency range greater than $0.5 \mathrm{~Hz}$, as most cortical neurons have a similar spatial orientation so that the many potential changes of individual neurons add up sufficiently. SDs can cooccur with two different types of depression of this spontaneous activity: nonspreading depression and spreading depression [24, 25]. In less ischemic or adequately supplied tissue with spontaneous activity, SD induces spreading depression of that activity. In contrast, neuronal hyperpolarization and nonspreading depression precede SD in severely ischemic brain regions so that SD occurs, but it cannot induce spreading depression in those regions. Only when SD reaches electrically active tissue during its migration can it then induce spreading depression. Importantly, SDs are fundamentally different from epileptic seizures and can be easily and unequivocally distinguished from them by ECoG [26]. Although SDs may cooccur with electrographic seizures during status epilepticus [27, 28], the type of excitability increase that leads to epileptic seizures is sometimes diametrically different from the type of excitability increase that leads to SDs [29-33]. Based on all these observations, it has been suggested that SD may serve as a real-time mechanistic biomarker for impending parenchyma damage in patients during neurocritical care $[24,34]$.

During neurocritical care, SDs are recorded subdurally with platinum/iridium (Pt/Ir) disposable electrodes, which are also used in the presurgical diagnostics of patients with epilepsy [35, 36]. This material is less suitable for recording DC potential shifts than silver/silver chloride $(\mathrm{Ag} / \mathrm{AgCl})$, the gold standard in experimental electrophysiology, but $\mathrm{Ag} / \mathrm{AgCl}$ is rightly banned for subdural use in humans because of neurotoxic side effects. Unfavorable properties of Pt electrodes are their polarizability and much higher impedance, which may exceed 100 kiloohm with small DC charging currents [37]. Alternatively, stainless steel can be clinically used for subdural ECoG. Stainless steel is relatively inexpensive but also polarizable, and its low-frequency noise is significantly higher than that of platinum $[35,37,38]$. Low-frequency noise stands for variations in the rate of drift in DC recordings due to slow spontaneous changes in electrode polarization. Thus, thin-film Pt electrodes are currently the best available option for the monitoring of SDs in humans $[36,39,40]$.

However, unfortunately, not all large DC shifts recorded in patients are SDs. Besides movement artifacts, there is at least one other type of DC artifact that is significantly more complex and specifically related to Pt electrodes. Thus, it was previously noted in two clinical cases that the interference of tissue partial pressure of oxygen $\left(\mathrm{p}_{\mathrm{ti}} \mathrm{O}_{2}\right)$ with subdural platinum electrodes produces DC artifacts $[19,41]$. These artifacts are particularly impressive when nurses or intensivists increase blood oxygenation by increasing the fraction of inspired oxygen $\left(\mathrm{FiO}_{2}\right)$ 
on the ventilator (Figs. 1a, 2a). In the present article, we systematically investigated these artifacts and compared them with SDs. Patients are typically subjected to brief episodes of hyperoxygenation before manipulations are performed on them, especially manipulations around the endotracheal tube. Clearly, it is important for monitoring SDs to correctly detect these $\mathrm{pO}_{2}$-induced $\mathrm{DC}$ shifts as artifacts even in the absence of simultaneous measurements of $\mathrm{p}_{\mathrm{ti}} \mathrm{O}_{2}$ with an intraparenchymal sensor. This is especially true because it is suspected that patient manipulations also simultaneously increase the risk for SDs [42]. A property of the $\mathrm{pO}_{2}$-induced $\mathrm{DC}$ artifacts that is surprising at first sight is that they can be simultaneously negative and positive in adjacent Pt electrodes. In further in vitro experiments, we took this as an opportunity to look more closely at $\mathrm{pO}_{2}$ and $\mathrm{pH}$ interferences of Pt electrodes to search for possible explanations of this peculiarity.

\section{Methods}

\section{Patients}

For the clinical study, we selected patients from a prospectively collected database using prespecified criteria, as described below. Table 1 provides demographic data. The protocol was approved by the ethics committee of the Charité - Universitätsmedizin Berlin. Either informed consent or surrogate informed consent was obtained for all patients, and research was conducted in accordance with the Declaration of Helsinki. Patients with aSAH consecutively enrolled in the Co-Operative Studies on Brain Injury Depolarizations (COSBID) at one center (Campus Virchow Klinikum, Berlin, Germany) were screened for study inclusion. Prospective inclusion criteria for COSBID have been described previously [43]. For this study, patients were further screened retrospectively for (1) the availability of DC/AC recordings (bandpass: $0-45 \mathrm{~Hz}$ ) of sufficient quality, (2) $\mathrm{p}_{\mathrm{ti}} \mathrm{O}_{2}$ recordings, and (3) at least one hyperoxygenation episode induced by an increase of $\mathrm{FiO}_{2}$ at the ventilator. Typically, $\mathrm{FiO}_{2}$ is briefly increased to $100 \%$ during such episodes. After the 6th consecutively screened patient with at least one hyperoxygenation episode, we analyzed the data. In total, 20 hyperoxygenation episodes could be analyzed.

\section{Neuromonitoring}

For the continuous DC/AC-ECoG recording, a six-contact, collinear Pt/Ir electrode strip (Wyler type, 5-mm diameter; 10-mm spacing; Ad-Tech Medical, Racine, WI) was placed on the cerebral cortex during aneurysm surgery as described previously [13, 14]. A subdermal $\mathrm{Pt} / \mathrm{Ir}$ needle electrode at the forehead was used as a quasi-reference for monopolar (= unipolar $=$ referential) recordings. Thus, the quasi-reference was well shielded from $\mathrm{p}_{\mathrm{ti}} \mathrm{O}_{2}, \mathrm{pH}$ and potential changes generated by the brain, but it was affected by systemic hyperoxia. In the rest of the article, $\mathrm{Pt} / \mathrm{Ir}$ electrodes are referred to simply as Pt electrodes. The full-band DC/AC-ECoG $(0-45 \mathrm{~Hz})$ was sampled at $200 \mathrm{~Hz}$ using a DC-coupled BrainAmp MR plus integrated amplifier and analog-digital converter and BrainVision Recorder software (Brain Products $\mathrm{GmbH}$, Gilching, Germany). The $\mathrm{p}_{\mathrm{ti}} \mathrm{O}_{2}$ was measured with a Clark-type intraparenchymal sensor (Licox CC1P1; Integra Lifesciences Corporation, Plainsboro, NJ) implanted below the brain surface next to the electrode strip as described previously $[14,43,44]$. In one of the patients with hyperoxygenation episodes, two $\mathrm{O}_{2}$ sensors were used. A subdural opto-electrode strip for the simultaneous measurement of DC/AC-ECoG and regional cerebral blood flow using laser Doppler flowmetry was placed in a subset of patients (Perimed AB, Järfälla, Sweden) $[12,14]$. The four integrated optodes were connected to a Periflux 5000 (Perimed AB). Data were sampled at $200 \mathrm{~Hz}$ with a PowerLab 16/SP analog-digital converter and LabChart software (ADInstruments, New South Wales, Australia). Nurses and intensivists typically increase blood oxygenation by increasing $\mathrm{FiO}_{2}$ at the ventilator before performing manipulations on the patient. This often leads to movement artifacts. Hyperoxygenation episodes were included in the analysis only if no movement artifacts were present in the corresponding DC/AC-ECoG traces.

\section{In vitro experiments}

Two chambers were filled with 5-mM phosphate buffer in $0.9 \% \mathrm{NaCl}$ and connected with a salt bridge made of soaked filter paper. The same Pt electrodes as for patient recordings and an $\mathrm{Ag} / \mathrm{AgCl}$ electrode were placed in the first chamber (= recording chamber) and connected to separate amplifier modules (LPBF-01GX; npi electronic $\mathrm{GmbH}$, Tamm, Germany). Reference electrodes of the same materials as the two different types of recording electrodes were placed in the second chamber and attached to the corresponding amplifier modules. Accordingly, they could not be affected by $\mathrm{pO}_{2}$ and $\mathrm{pH}$ changes in the recording chamber. Amplifier modules were connected to a Power1401 mk II analog-digital converter (Cambridge Electronic Design Limited, Cambridge, UK). Copper $(\mathrm{Cu})$ electrodes attached to the digital-analog converter output of the Power1401 were used for the external application of electric current to the experimental setup. A pH meter and $\mathrm{O}_{2}$-sensitive probe (Picoammeter PA 2000; Unisense, Aarhus, Denmark) were placed in the recording chamber. In contrast with the solution in the reference chamber, the solution in the recording chamber was continuously bubbled with a mixture of $\mathrm{O}_{2}$ and $\mathrm{N}_{2}$. The $\mathrm{pO}_{2}$ was set by adjusting the 
$\mathrm{O}_{2}: \mathrm{N}_{2}$ ratio until the desired value was reached while the total gas flow was kept constant (Supplemental Fig. 1). Changes in $\mathrm{pH}$ were achieved by addition of either $\mathrm{NaOH}$ or $\mathrm{HCl}$ and verified by the $\mathrm{pH}$ meter.

After all electrodes and probes were placed, the $\mathrm{pH}$ in the recording chamber was set to 7.4 and $\mathrm{pO}_{2}$ to a baseline of $50 \mathrm{mmHg}$. The electrodes were allowed to stabilize until the DC drift of the Pt electrodes was less than $0.4 \mathrm{mV} / \mathrm{min}$. The effect of changes in $\mathrm{pO}_{2}$ was then tested in subsequent steps from $50 \mathrm{mmHg}$ to (1) $0 \mathrm{mmHg}$, (2) $50 \mathrm{mmHg}$, (3) $150 \mathrm{mmHg}$, and (4) $50 \mathrm{mmHg}$. The same sequence of changes in $\mathrm{pO}_{2}$ was then repeated during a $\mathrm{pH}$ of 6.4 and during a $\mathrm{pH}$ of 8.4. After each environmental change, electrodes were given sufficient time to stabilize. During each $\mathrm{pO}_{2} / \mathrm{pH}$ combination, a square voltage pulse with an amplitude of $-50 \mathrm{mV}$ and duration of 5 min was applied via the stimulation electrode. Only the plateau phase of the voltage curve was used for reading the square pulse amplitude (Fig. 3a).

\section{Results}

\section{Human recordings}

Hyperoxygenation episodes by increasing $\mathrm{FiO}_{2}$ at the ventilator started from a $\mathrm{p}_{\mathrm{ti}} \mathrm{O}_{2}$ baseline of 37 (30-40) $\mathrm{mmHg}$ (median, interquartile range) and reached 71 (50-97) $\mathrm{mmHg}$ (Fig. 1a). During a total of 20 episodes on each of six subdural platinum electrodes in six patients, we observed 95 predominantly negative responses in six patients and 25 predominantly positive responses in four patients. During the same episode, adjacent electrodes could simultaneously show positive and negative responses (Figs. 1a, 2a). The median amplitude of the 95 negative DC responses was $6.2(4.5-10.4) \mathrm{mV}$ and the amplitude of the 25 positive responses was 7.6 (4.4-10.4) mV. Importantly, the amplifier did not allow us to determine the true baseline voltage of the respective DC recordings. The automatic offset correction alone, which the amplifier performs separately for each channel, thwarts this. Furthermore, a biological electrical voltage source is known to be located between the subdermal and subdural compartments [45-49], and not only the subdural Pt electrodes but also the subdermal Pt quasireference is exposed to different chemical adsorbents, $\mathrm{pH}$ changes, and $\mathrm{pO}_{2}$ changes. Thus, it remained unclear in these measurements whether individual subdural Pt electrodes were negatively polarized, positively polarized, or nonpolarized before the onset of artificial hyperoxygenation episodes.

To highlight the different nature between $\mathrm{pO}_{2}$-induced DC artifacts at the Pt electrodes and SDs, we show an SD inducing spreading hyperoxia (Fig. 1b) and another SD inducing spreading hypoxia (Fig. 1c) [14, 43, 44, 50]. These $\mathrm{SD}$-induced $\mathrm{O}_{2}$-responses were measured with two intracortical $\mathrm{O}_{2}$ sensors at a distance of approximately $1 \mathrm{~cm}$ from each other. In contrast to SD-induced spreading hyperoxia and SD-induced spreading hypoxia in the tissue, the artificial hyperoxygenation episode in Fig. 1a was characterized by the simultaneous occurrence of the $\mathrm{p}_{\mathrm{ti}} \mathrm{O}_{2}$ increase at both intraparenchymal $\mathrm{O}_{2}$ sensors. Figure $2 \mathrm{~b}$ provides further criteria for how to distinguish $\mathrm{pO}_{2}$-induced $\mathrm{DC}$ artifacts from SDs. Thus, SD in electrically active tissue leads to a spreading depression of spontaneous activity. This is observed in the ACECoG recordings as a rapidly developing reduction in the amplitudes of spontaneous activity that spreads together with SD between adjacent recording sites [36]. In contrast, we did not find significant changes in spontaneous activity during the artificial hyperoxygenation episodes. Furthermore, SD is known to induce tone alterations in resistance vessels, causing either transient hyperperfusion (physiological hemodynamic response) in healthy tissue or initial hypoperfusion (inverse hemodynamic response $=$ spreading ischemia) in tissue where the neurovascular unit is disturbed [12, 24, 51]. Normal and inverse hemodynamic responses to SD typically occur along a continuum in the tissue [1]. The SD in Fig. 2b shows a slightly inverse hemodynamic response at all three optodes. In contrast, we found no significant hemodynamic changes during the artificial hyperoxygenation episodes (Fig. 2a). Table 2 provides an overview of the differences between $\mathrm{pO}_{2}$-induced DC artifacts and SDs.

\section{Changes in $\mathrm{pO}_{2}$ and $\mathrm{pH}$ result in $\mathrm{DC}$ shifts at $\mathrm{Pt}$ electrodes}

The simple placement of the $\mathrm{Cu}$ electrode for stimulation in the in vitro recording chamber induced a DC change in the positive direction at the Pt electrodes. For this, no external current had to be applied. Increases in $\mathrm{pO}_{2}$ from the baseline, then, always led to additional positive DC shifts under this condition of a positive electrode polarization (Fig. 3b). External application of a constant negative voltage with an amplitude of $1 \mathrm{~V}$ to the stimulation electrodes subsequently led to a persistent negative DC change at the Pt electrodes and an increase in noise that was most intense around $0.5 \mathrm{~Hz}$. Under this condition of a negative electrode polarization, increases in $\mathrm{pO}_{2}$ from baseline always led to additional negative DC shifts (Fig. 3b). Accordingly, this experiment suggested that the hyperoxygenation-induced DC artifacts at the Pt electrodes could depend on the direction in which the respective electrodes are polarized under baseline conditions.

In six other experiments, we investigated only the lownoise condition of positive electrode polarization without external current application as an example. Under this condition, we determined the $\mathrm{DC}$ responses to $\mathrm{pO}_{2}$ and $\mathrm{pH}$ changes in the recording chamber. The $\mathrm{Pt}$ 


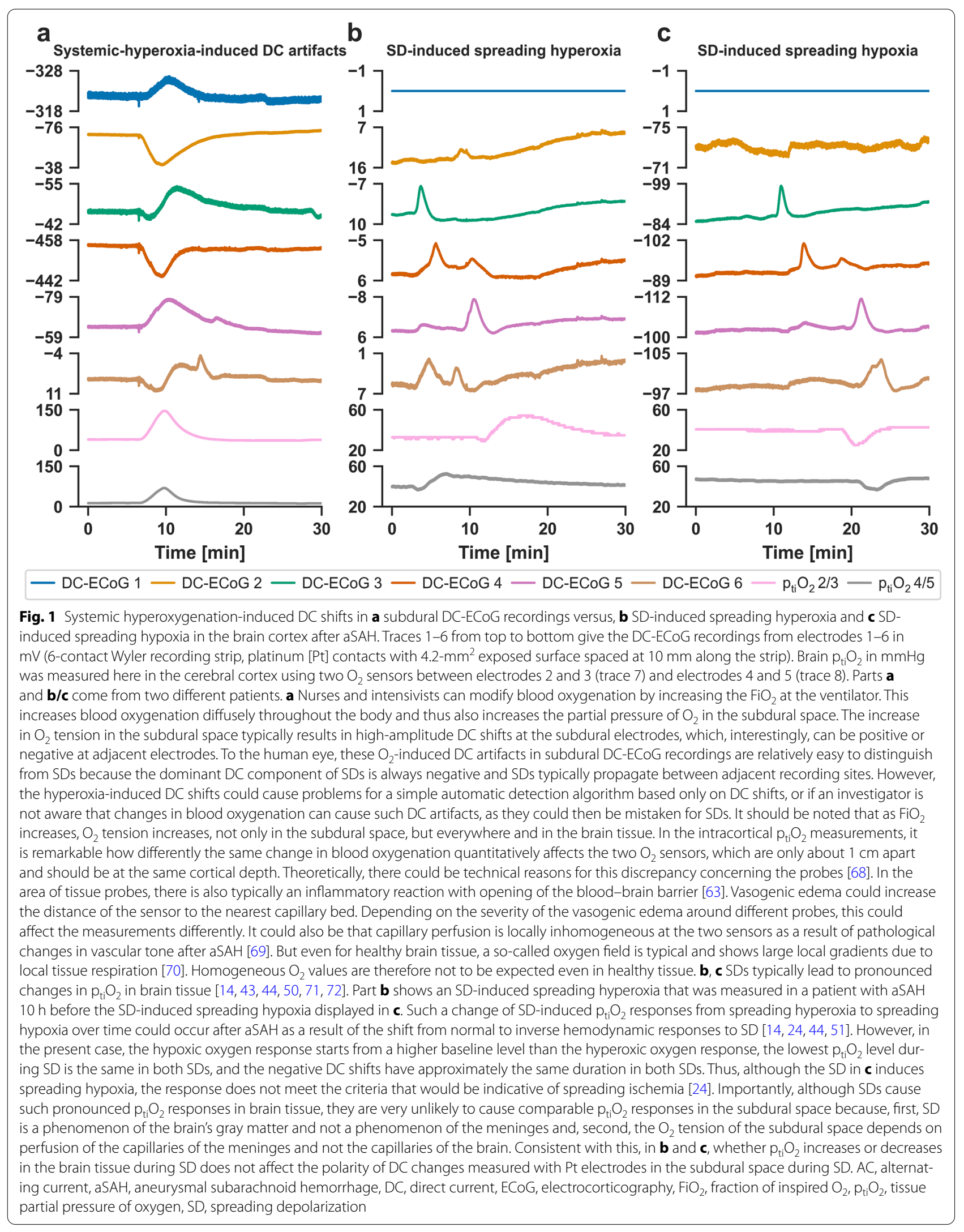




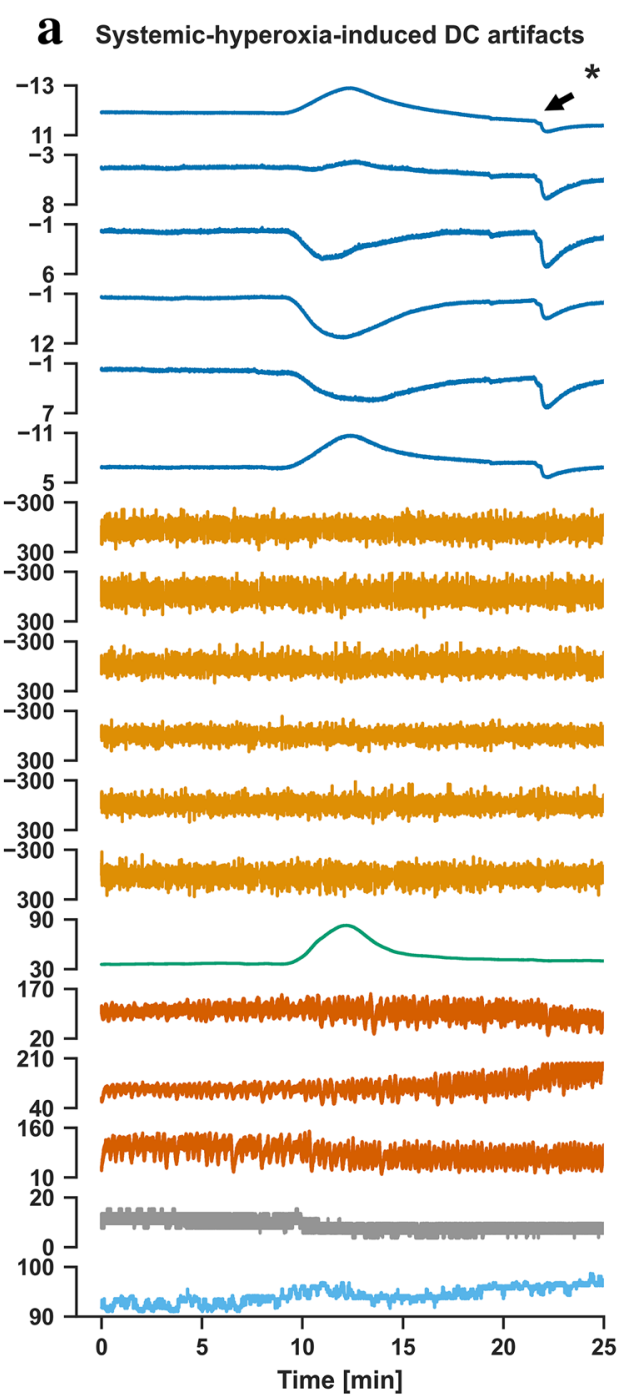

\section{b SD-induced spreading hypoxia}

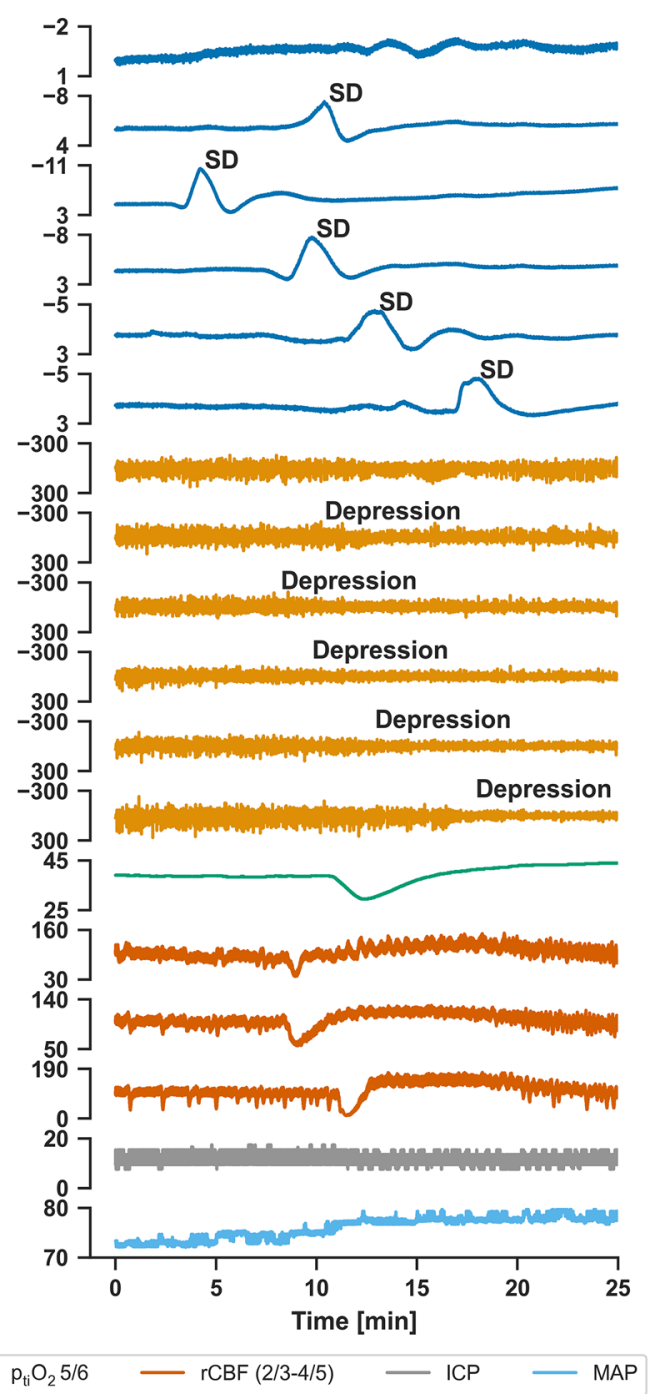

Fig. 2 Multimodal recordings of $\mathbf{a}$ systemic hyperoxygenation-induced DC artifacts versus $\mathbf{b}$ SD-induced spreading hypoxia in the same patient with aSAH. Traces 1-6 from top to bottom give the DC-ECoG recordings from electrodes 1-6 in mV (* represents movement artifact). Traces 7-12 show the bandpass filtered AC-ECoG of the same electrodes in $\mu \mathrm{V}$ (frequency band between 0.5 and $45 \mathrm{~Hz}$ ). Trace 13 shows $p_{\mathrm{ti}} \mathrm{O}_{2}$ recorded in $\mathrm{mmHg}$ with an intracortical sensor between electrodes 5 and 6. Traces 14-16 show rCBF measured with optodes between electrodes 2 and 3 , 3 and 4 , and 4 and 5 from top to bottom by laser Doppler flowmetry. Trace 17 provides the intracranial pressure in mmHg measured using an extraventricular drainage catheter and trace 18 the mean arterial pressure in $\mathrm{mmHg}$ measured using a catheter in the radial artery. In addition to the fact that the dominant DC component of SDs is always negative and SDs typically propagate between adjacent recording sites, there are other criteria that help to distinguish SDs from $\mathrm{O}_{2}$-induced DC artifacts. These include, for example, that SD typically induces spreading depression of spontaneous activity in tissue with spontaneous electrical activity. SD-induced spreading depression is observed in the AC-ECoG recordings as a rapidly developing reduction in the amplitudes of spontaneous activity which spreads together with SD between adjacent recording sites. In addition, SD induces characteristic rCBF changes. In healthy tissue, an increase in rCBF typically dominates initially, which is called spreading hyperemia, and is followed by a mild decrease in blood flow called oligemia [73]. In contrast, under pathological conditions, instead of an initial vasodilation, SD can induce a severe initial vasoconstriction (equals inverse hemodynamic response), which can be long-lasting and lead to impaired neuronal repolarization with prolongation of SD as a consequence of an insufficient supply with oxidative substrates [51]. This phenomenon is called spreading ischemia and may lead to infarction after a certain duration both in animals and humans $[12,74]$. The hemodynamic responses to SD typically show a continuum across tissue from an inverse ischemic response to an increasingly normal hyperemic response or the other way round. In the present case, we see that SD induces inverse rCBF responses at all three optodes, but these are not yet of precarious proportions, because there is a relatively rapid recovery of $\mathrm{rCBF}$. The initial drop in $\mathrm{rCBF}$ is then followed by a transient hyperemia which is typical of such inverse responses. $\mathrm{AC}$, alternating current, aSAH, aneurysmal subarachnoid hemorrhage, $\mathrm{DC}$, direct current, $\mathrm{ECoG}$, electrocorticography, MAP, mean arterial pressure, $\mathrm{p}_{\mathrm{ti}} \mathrm{O}_{2}$, tissue partial pressure of oxygen, rCBF, regional cerebral blood flow, SD, spreading depolarization 
Table 1 Baseline characteristic of the patients

\begin{tabular}{|c|c|c|c|c|c|c|c|}
\hline No & Age (year) & Sex & WFNS grade & $\begin{array}{l}\text { Modified Fisher } \\
\text { scale [75] }\end{array}$ & $\begin{array}{l}\text { Location } \\
\text { of aneurysm }\end{array}$ & Treatment & Location of electrode \\
\hline 1 & 62 & Female & 4 & 3 & ACOP-L & Clipping & Left frontal lobe \\
\hline 2 & 55 & Male & 5 & 4 & $\mathrm{ACOA}$ & Clipping & Right frontal lobe \\
\hline 3 & 70 & Female & 4 & 4 & $\mathrm{ICA}-\mathrm{L}$ & Clipping & Left frontal lobe \\
\hline 4 & 79 & Female & 4 & 4 & MCA-L & Clipping & Left frontal lobe \\
\hline 5 & 39 & Male & 4 & 4 & PericA-L & Clipping & Right frontal lobe \\
\hline 6 & 54 & Male & 1 & 3 & $\mathrm{ACOA}$ & Clipping & Right frontal lobe \\
\hline
\end{tabular}

$A C O A$ anterior communicating artery, $A C O P$ posterior communicating artery, ICA internal carotid artery, $L$ left, $M C A$ middle cerebral artery, PericA pericallosal artery, WFNS World Federation of Neurosurgical Societies

electrodes showed a baseline of 136.9 (131.1-147.0) mV at the onset of the experiments when $\mathrm{pH}$ was 7.4 and $\mathrm{pO}_{2}$ was at $50 \mathrm{mmHg}$ (Fig. 4a). Decrease in $\mathrm{pO}_{2}$ to $0 \mathrm{mmHg}$ resulted in a negative DC shift with an amplitude of 38.5 (36.2-51.2) $\mathrm{mV}$ and return to $50 \mathrm{mmHg}$ in a positive DC shift with an amplitude of 42.4 (34.6-48.2) mV. A further increase to $150 \mathrm{mmHg}$ led to a positive DC shift with an amplitude of only $15.9(15.3-16.6) \mathrm{mV}$, indicating that the effect of $\mathrm{pO}_{2}$ on the DC potential was nonlinear. Acidification from a pH of 7.4 to 6.4 led to a positive DC shift of 13.5 (7.7-19.9) $\mathrm{mV}$ and alkalinization from a $\mathrm{pH}$ of 7.4 to 8.4 to a negative DC shift of $7.3(11.6-5.4) \mathrm{mV}$. The $\mathrm{pO}_{2}$-induced DC shifts were similar under $\mathrm{pH} 6.4,7.4$ or 8.4. The $\mathrm{Ag} / \mathrm{AgCl}$ electrode was also influenced by the environmental changes but to a much lesser extent than the Pt electrodes (Fig. 4a).

\section{Influence of $\mathrm{pO}_{2}$ and $\mathrm{pH}$ on the $\mathrm{Pt}$ recorded square voltage pulses}

In the six experiments, we additionally investigated whether the $\mathrm{pO}_{2}$ changes and $\mathrm{pH}$ changes modified $\mathrm{DC}$ field potential changes in response to square voltage pulses with an amplitude of $-50 \mathrm{mV}$ and a duration of $5 \mathrm{~min}$. In response to a square voltage pulse of $-50 \mathrm{mV}$, the $\mathrm{Ag} / \mathrm{AgCl}$ electrode recorded a DC shift of 45.5 (45.245.9) $\mathrm{mV}$ at a $\mathrm{pH}$ of 7.4 and a $\mathrm{pO}_{2}$ of $50 \mathrm{mmHg}$. During all investigated combinations of $\mathrm{pO}_{2}$ in neutral and acidic $\mathrm{pH}$, the amplitude of the recorded negative DC shift was in the range between 43.0 and $47.0 \mathrm{mV}$ (Fig. 4b). The Ag/ $\mathrm{AgCl}$ electrode showed worse performance in alkaline than in neutral or acidic medium increasing the measurement range to $33.8-54.6 \mathrm{mV}$. Pt electrodes performed always worse than the $\mathrm{Ag} / \mathrm{AgCl}$ electrode. Their poorest performance was under anoxic conditions, where they indicated little more than $50 \%$ of the true negative DC field potential shift (example in Fig. 3a) and showed the largest variability (Fig. 4b). Median and interquartile range of the amplitudes measured on $\mathrm{Pt}$ and $\mathrm{Ag} / \mathrm{AgCl}$ electrodes during $50 \mathrm{mV}$ square voltage pulses under different $\mathrm{pO}_{2}$ and $\mathrm{pH}$ values are given in Table 3 .

\section{Discussion}

Transient worsening of mismatch between oxidative substrate supply and demand was a potent stimulus for delayed SDs in a previous study in mice after middle cerebral artery occlusion [42]. Such transient worsening could result not only from systemic arterial blood pressure fluctuations but also, for example, from sensory stimulation of metabolically unstable cortical representation fields. It is therefore likely that manipulations on patients during neurocritical care may lead to SDs in some circumstances. Potentially, SDs triggered in this way could contribute to lesion growth $[4,5,52]$. Therefore, in neuromonitored patients in the intensive care unit, it is recommended to pay attention to whether SDs occur during manipulations [42]. On the other hand, patients are typically subjected to brief episodes of hyperoxygenation before manipulations are performed on them, especially manipulations around the endotracheal tube. In the present work, we have investigated $\mathrm{pO}_{2}$-induced DC shifts that result as electrode artifacts from such hyperoxygenation episodes. They should not be confused with SDs.

The magnitude of the $\mathrm{pO}_{2}$-induced subdural $\mathrm{DC}$ artifacts by approximately $6 \mathrm{mV}$ is exactly in the same range as DC shifts from SDs, but DC shifts of SDs typically show a sequential onset at adjacent recording sites and their steep, initial component is always predominantly negative in full-band subdural recordings $[14,22,53,54]$. In contrast, $\mathrm{pO}_{2}$-induced $\mathrm{DC}$ artifacts started simultaneously at all electrodes and, surprisingly, they could be negative and positive at adjacent electrodes at the same time. Other differences between $\mathrm{pO}_{2}$-induced electrode artifacts and SDs are summarized in Table 2.

We found that the change in polarity of the $\mathrm{pO}_{2}$-induced $\mathrm{DC}$ artifacts in our in vitro experiments 

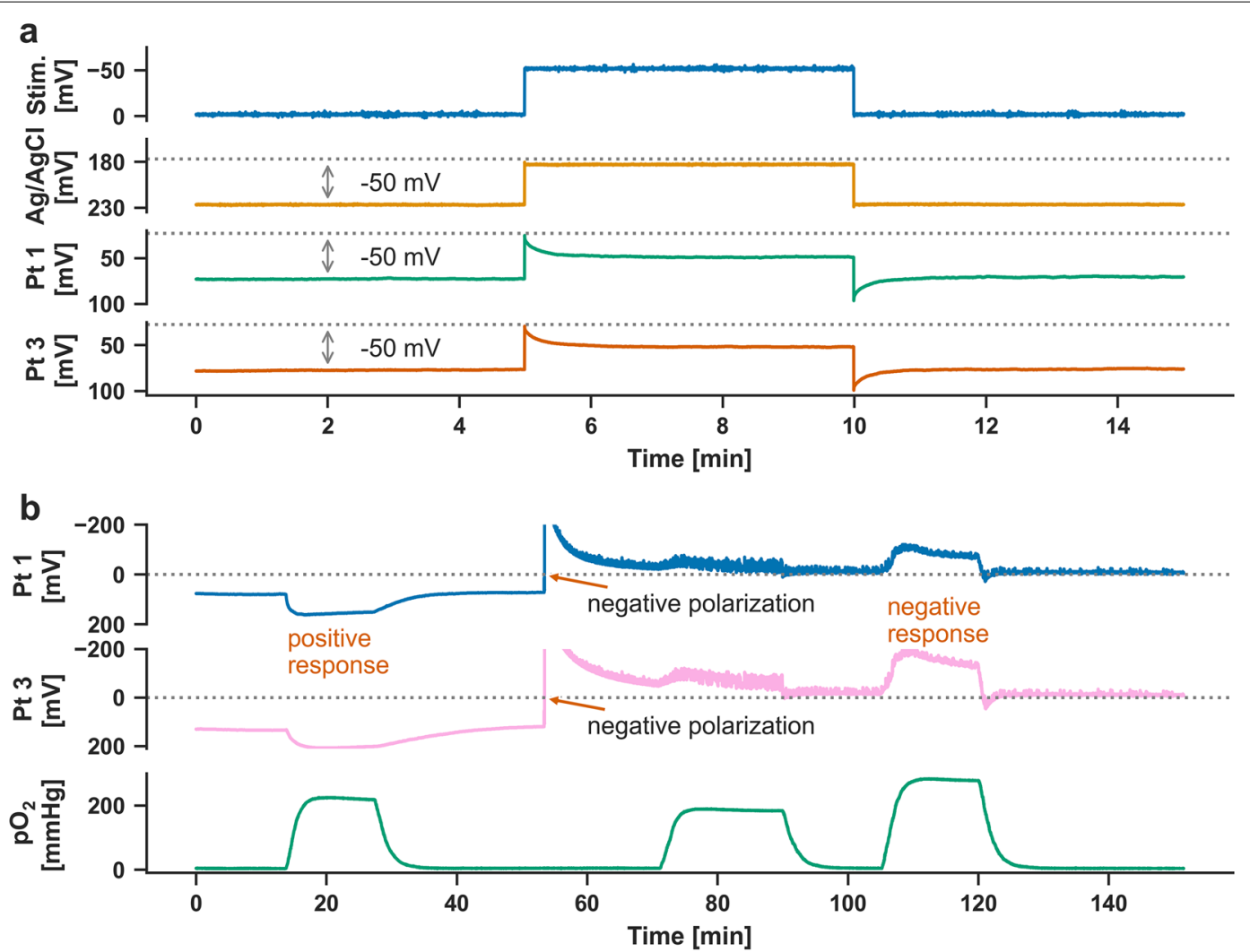

Fig. 3 Electrode polarization and effect of positive and negative polarization of Pt electrodes on $\mathrm{pO}_{2}$-induced $\mathrm{DC}$ artifacts. Electrodes are used to transduce changes in electric potentials into electric currents required by wires and electronic instrumentation. Electrodes consist of electric conductors in contact with the ionic fluids. At the interface between electrode and ionic solution (electric double layer) oxidation-reduction reactions need to occur for a charge to be transferred between electrode and solution. For most electrodes, the cations in solution are of the same metal as the electrode material. The metal atoms either give up electrons (oxidation) and go into solution as positively charged ions or, vice versa, the positively charged metal ions in the solution accept electrons (reduction) and the metal is deposited at the electrode. A commonly used electrode of this type is the $\mathrm{Ag} / \mathrm{AgCl}$ electrode. The $\mathrm{Ag} / \mathrm{AgCl}$ electrode is characterized by fast kinetics. This means that the redox reactions (either cathodic deposition of the silver ions or anodic dissolution of the silver metal) are very fast, so the potential of the electrode will not change significantly from its equilibrium potential even if a large, slowly varying voltage is applied to the electrode. This behavior results in a low resistance allowing a high current to pass through the electrode. Therefore, the $\mathrm{Ag} / \mathrm{AgCl}$ electrode is ideally suited to measure not only changes in $\mathrm{AC}$ potential but also DC potential. Electrodes with this behavior in electrical resistance are called nonpolarizable or reversible. Accordingly, electrodes with the opposite behavior are called polarizable. Polarization means that the electrode potential will change significantly from its equilibrium potential with the application of even a small current density because the redox reactions are inherently too slow. The temporary disturbance of the electric double layer at such electrodes by the externally applied voltage leads to only a very small current flow after the first surge, thus indicating a high resistance. This means that the electrode acts as a capacitor: DC is blocked while AC is allowed. Hence, an ideally polarizable electrode will only permit the measurement of AC but not the measurement of DC potentials. However, ideally polarizable electrodes without charge transfer across the interface do not occur in the real world. So-called easily polarizable electrode materials are rather found such as Pt. These can be used to measure DC potentials, but they do so with more or less distortion from the true signal. The nature of this distortion is that of an overpotential, usually calculated as the difference in the electrode potential between the electrode's equilibrium potential and its operating potential when a current is flowing. As explained above, the electrode's inherent speed determines the value of the overpotential: the slower the redox reactions, the larger the overpotential for a given current density. a DC pulse response recorded on Pt and $\mathrm{Ag} / \mathrm{AgCl}$ electrodes at $\mathrm{pH}$ at 7.4 and $\mathrm{pO}_{2}$ at $0 \mathrm{mmHg}$. In contrast to the $\mathrm{Ag} / \mathrm{AgCl}$ electrode, the Pt electrode shows a clear distortion from the true signal. Under anoxic conditions, the DC amplitude indicated by the Pt electrode after equilibration was barely half the true DC field potential change given by the external voltage source. In contrast, the $\mathrm{Ag} / \mathrm{AgCl}$ electrode displayed the true DC shift almost perfectly. Note that negative voltage changes are shown here as upward deflections following the EEG polarity convention. $\mathbf{b}$ The deflection of the Pt electrode-measured $\mathrm{pO}_{2}$-induced $\mathrm{DC}$ artifact in the negative or positive direction depended on the negative or positive electrode polarization, respectively, before the $\mathrm{pO}_{2}$ increase. An increase in $\mathrm{pO}_{2}$ increased the absolute magnitude of the voltage change measured on the Pt electrodes while preserving the polarity so that the $\mathrm{pO}_{2}$ increase induced either a positive response starting from a positive baseline or a negative response starting from a negative baseline. AC, alternating current, $\mathrm{Ag} / \mathrm{AgCl}$, silver/silver chloride, DC, direct current, EEG, electroencephalography, Pt, platinum 
Table 2 Comparison of $\mathrm{pO}_{2}$-induced DC artifacts and SD

\begin{tabular}{|c|c|c|}
\hline Feature & Systemic-hyperoxia-induced DC artifact & Spreading depolarization \\
\hline $\begin{array}{l}\text { Polarity of DC shift in full-band subdural record- } \\
\text { ings to a theoretical limit of } 0 \mathrm{~Hz}\end{array}$ & Negative or positive & $\begin{array}{l}\text { The steep, initial main component is always pre- } \\
\text { dominantly negative }\end{array}$ \\
\hline Spread of DC shift & Never & Usually, clear spread between adjacent channels \\
\hline Occurrence in adjacent channels & Occurs in all channels & $\begin{array}{l}\text { Some electrodes may not be reached by the SD } \\
\text { and therefore these channels do not participate } \\
\text { in the DC shift }\end{array}$ \\
\hline Duration of DC changes & $\begin{array}{l}\text { Depends on the intensivist/nurse that } \\
\text { increases the fraction of inspired } \mathrm{O}_{2}\end{array}$ & $\begin{array}{l}\text { The negative DC shift can last from approximately } \\
50 \mathrm{~s}[14,53,54] \text { to infinity depending on baseline } \\
\text { regional cerebral blood flow, baseline tissue } \\
\text { partial pressure of } \mathrm{O}_{2} \text {, cerebral metabolic rate } \\
\text { of } \mathrm{O}_{2} \text { and the hemodynamic response to SD, an } \\
\text { infinite negative DC shift can occur, for example, } \\
\text { during the development of a cerebral infarction } \\
\text { or during dying }[12,17-19]\end{array}$ \\
\hline Depression of spontaneous brain activity & No depression & $\begin{array}{l}\text { Spreading depression if spontaneous activity was } \\
\text { present at onset of SD and AC-ECoG recordings } \\
\text { are of sufficient quality; spreading depression } \\
\text { is observed in AC-ECoG recordings as a rapidly } \\
\text { developing reduction in the amplitudes of spon- } \\
\text { taneous activity }\end{array}$ \\
\hline Regional cerebral blood flow response & No significant change & $\begin{array}{l}\text { Either spreading hyperemia (normal response) } \\
\text { or spreading ischemia (inverse response) or no } \\
\text { change }\end{array}$ \\
\hline $\begin{array}{l}\mathrm{O}_{2} \text { response if recorded with } \mathrm{O}_{2} \text { sensors at differ- } \\
\text { ent locations }\end{array}$ & Simultaneous increase at adjacent $\mathrm{O}_{2}$ sensors & $\begin{array}{l}\text { Either spreading hyperoxia or spreading hypoxia or } \\
\text { no change }\end{array}$ \\
\hline
\end{tabular}

$A C$ alternating current, $D C$ direct current, $E C O G$ electrocorticography, SD spreading depolarization

could be produced by reversing the polarization of a Pt cathode (Fig. 3b). When no voltage was applied, the arrangement of $\mathrm{Pt}$ cathode and $\mathrm{Cu}$ anode constitutes a galvanic cell in which the Pt cathode is positively charged according to the positions of $\mathrm{Pt}$ and $\mathrm{Cu}$ in the electrochemical series. When the Pt cathode was negatively polarized by a constant voltage of approximately $1 \mathrm{~V}$, the galvanic cell was turned into a so-called electrolytic cell, in which redox reactions take place that normally do not occur voluntarily, i.e., chemical reactions are forced to take place in the opposite direction instead of in their normally energetically favorable direction. Through the universal concept of energy, these paradoxical redox reactions, like normal redox reactions, are associated with electrical voltage changes that can be calculated using the Nernst equation. If chemical reactions are forced in an electrolytic cell, which are accompanied by voltage changes and proceed in the opposite direction to the galvanic cell, it may be hypothesized that not only the direction of the chemical reactions but also the polarity of the voltage changes is reversed in the electrolytic compared to the galvanic cell. This could be a basic explanation for the polarization-dependent change in polarity of the $\mathrm{pO}_{2}$-induced $\mathrm{DC}$ artifacts.

The exact description of the underlying redox reactions is however beyond the scope of this clinical paper as the electrochemical reaction of $\mathrm{O}_{2}$ at a Pt surface is surprisingly complex, even in an aqueous electrolyte solution without additional chemical species. This socalled oxygen reduction reaction at the Pt surface is in fact one of the best studied chemical reactions, but its details are still considered not understood in chemistry today. In the simple version, $\mathrm{O}_{2}$ is spontaneously reduced to water in a 4-electron process via at least two different routes $\left(\mathrm{O}_{2}+4 \mathrm{e}^{-}+4 \mathrm{H}^{+} \leftrightarrows 2 \mathrm{H}_{2} \mathrm{O}\right.$ or $\mathrm{O}_{2}+2 \mathrm{e}^{-}+2$ $\mathrm{H}^{+} \leftrightarrows 2 \mathrm{H}_{2} \mathrm{O}_{2}$ ) at near neutral pH [55]. The kinetics of this reaction depend on the solution $\mathrm{pH}$, electrolytes, pretreatment of the Pt surface, $\mathrm{pO}_{2}$ and the electrode polarization [55-57]. Under atmospheric pressure, at nearly neutral $\mathrm{pH}$ and low or negatively polarized $\mathrm{Pt}$ cathode, chemisorbed hydroxyl ions are formed as the dominant intermediate surface oxide during $\mathrm{O}_{2}$ adsorption and reduction, as was suggested by several authors [56-58]. It is assumed that the latter is the decisive redox reaction via which $\mathrm{pO}_{2}$ is measured in so-called Clarktype electrodes, which consist of an electrolytic cell with $\mathrm{Pt}$ cathode and Ag anode. For this reaction to proceed efficiently in a physiological electrolyte at near neutral $\mathrm{pH}$ and ambient pressure, a substantial negative polarization of approximately $200 \mathrm{mV}$ or more versus the standard hydrogen electrode is required. It could be argued that strong negative polarization, which would be sufficient for this response, is not expected per se at the subdural Pt electrodes in patients in situ because the electrodes are 


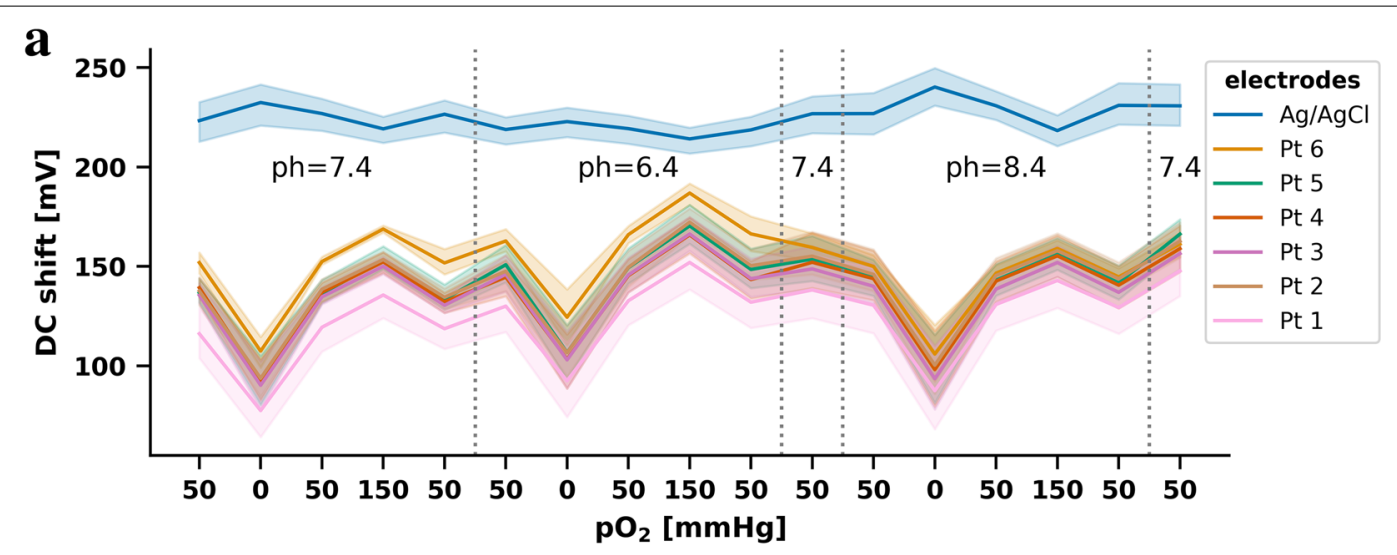

b

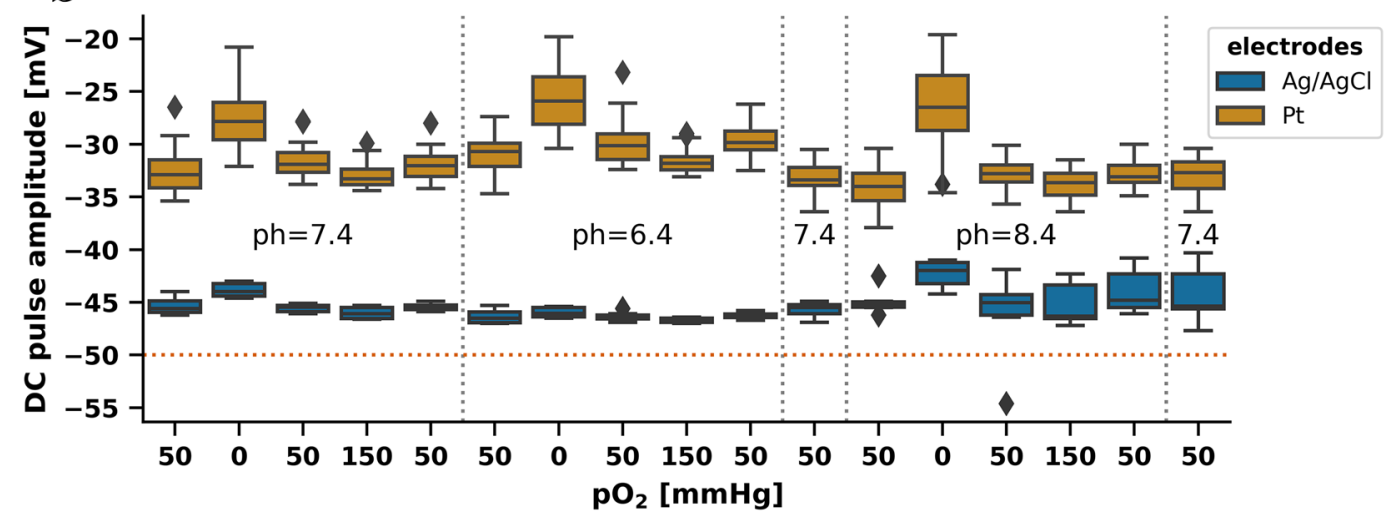

Fig. 4 Effects of $\mathrm{pO}_{2}$ and $\mathrm{pH}$ changes on the $\mathrm{DC}$ potential, and $\mathrm{DC}$ pulse responses under different conditions of $\mathrm{pO}_{2}$ and $\mathrm{pH}$. a Changes in $\mathrm{pO}_{2}$ and $\mathrm{pH}$ markedly shifted the DC voltage at the Pt electrodes in a nonlinear fashion. The DC shift amplitudes due to $\mathrm{pO}_{2}$ changes did not differ between different $\mathrm{pH}$ values, but the shift in $\mathrm{pH}$ itself also induced DC shifts. The lines represent the mean and the shading the $95 \%$ confidence interval of the measured values for each electrode across all experiments. From left to right, each line starts at the baseline value which was measured at a $\mathrm{pO}_{2}$ of $50 \mathrm{mmHg}$ and a pH of 7.4, and the voltage changes from one condition to the next condition are shown. The polarity of the shifts in relation to the preceding condition is given by the $y$-axis of the graph. Note that positive voltage changes are shown in this more technical figure as upward deflections. Values were determined after a given $\mathrm{pO}_{2}$ or $\mathrm{pH}$ change, when the electrodes had stabilized and before the square voltage pulse was applied. b During the different levels of $\mathrm{pO}_{2}$ and $\mathrm{pH}$, we applied 5 min-long, negative square voltage pulses with an amplitude of $50 \mathrm{mV}$ to test whether the effect of electrode polarization varies at different $\mathrm{pO}_{2}$ and $\mathrm{pH}$ levels. The amplitude of the square $-50 \mathrm{mV}$ pulse (marked with a red horizontal line) was never perfectly reproduced by either $\mathrm{Ag} / \mathrm{AgCl}$ or Pt electrodes but the measurements with the $\mathrm{Ag} / \mathrm{AgCl}$ electrode were always superior to the measurements with the Pt electrodes. The Pt electrodes showed the poorest performance under anoxic conditions. Ag/AgCl, silver/silver chloride, DC, direct current, Pt, platinum

not connected to any obvious current source. However, it is well known that transient surface oxides can easily form at Pt surfaces under normal atmospheric conditions exhibiting a surprising variety of structural patterns [56, 57]. The actual electrochemical processes at the surface of the Pt electrodes in patients in situ will be even more complex than in test tubes due to adsorbed molecules such as, for example, various hemoglobin species containing either $\mathrm{Fe}^{2+}$ or $\mathrm{Fe}^{3+}$ ions. Hemoglobin molecules could get into contact with the Pt electrodes in situ because the electrodes were implanted in patients after aSAH. In addition to hemoglobins, other proteins, small aromatic molecules, and/or thiol compounds could be adsorbed at the Pt surface, further modifying the features of the electrodes. Therefore, even a passively recording Pt electrode may become partially polarized, e.g., due to local currents [38], and the polarization between adjacent electrodes could differ due to locally different concentrations of adsorbed molecules. Accordingly, different polarities of $\mathrm{pO}_{2}$-induced $\mathrm{DC}$ artifacts would result. The $\mathrm{Cu}$ electrode is a rather artificial addition generating chemical current in our in vitro setup. However, we consider the $\mathrm{Cu}$ electrode as a placeholder of biological current sources known to exist in vivo. For example, the cortical surface of the physiological mammalian brain is steadily 
Table 3 Amplitudes measured on $\mathrm{Pt}$ and $\mathrm{Ag} / \mathrm{AgCl}$ electrodes during $50-\mathrm{mV}$ square voltage pulses under different $\mathrm{pO}_{2}$ and $\mathrm{pH}$ values

\begin{tabular}{|c|c|c|c|c|c|c|}
\hline $\mathrm{pH}$ & 7.4 & & & & & \\
\hline $\mathrm{pO}_{2}(\mathrm{mmHg})$ & 50 & 0 & 50 & 150 & 50 & \\
\hline $\mathrm{Ag} / \mathrm{AgCl}(\mathrm{mV})(n=6)$ & $46(45-46)$ & $44(43-44)$ & $45(45-46)$ & $46(46-47)$ & $46(45-46)$ & \\
\hline $\operatorname{Pt}(m V)(n=36)$ & $33(32-34)$ & $28(26-30)$ & $32(31-33)$ & $33(32-34)$ & $32(31-33)$ & \\
\hline $\mathrm{pH}$ & 6.4 & & & & & 7.4 \\
\hline $\mathrm{pO}_{2}(\mathrm{mmHg})$ & 50 & 0 & 50 & 150 & 50 & 50 \\
\hline $\mathrm{Ag} / \mathrm{AgCl}(n=6)(\mathrm{mV})$ & $46(46-47)$ & $46(46-46)$ & $46(46-47)$ & $47(47-47)$ & $46(46-46)$ & $46(45-46)$ \\
\hline $\operatorname{Pt}(n=36)(\mathrm{mV})$ & $31(30-32)$ & $26(24-28)$ & $30(29-31)$ & $32(31-32)$ & $30(29-31)$ & $33(32-34)$ \\
\hline $\mathrm{pH}$ & 8.4 & & & & & 7.4 \\
\hline $\mathrm{pO}_{2}(\mathrm{mmHg})$ & 50 & 0 & 50 & 150 & 50 & 50 \\
\hline $\mathrm{Ag} / \mathrm{AgCl}(n=6)(\mathrm{mV})$ & $45(45-45)$ & $42(41-43)$ & $45(44-46)$ & $46(43-47)$ & $45(42-46)$ & $45(42-46)$ \\
\hline $\operatorname{Pt}(n=36)(\mathrm{mV})$ & $34(33-35)$ & $27(23-29)$ & $33(32-34)$ & $34(33-35)$ & $33(32-34)$ & $33(32-34)$ \\
\hline
\end{tabular}

An ideal electrode would measure $50 \mathrm{mV}$. Ag/AgCl electrodes also failed to reach $50 \mathrm{mV}$, but Pt electrodes were clearly worse. Data are presented as medians and interquartile ranges

$\mathrm{Ag} / \mathrm{AgCl}$ silver/silver chloride, DC direct current, Pt platinum

positive to other parts of the nervous system such as the cerebral ventricles by approximately $10-20 \mathrm{mV}$ [45-49].

However, there could also be an alternative more trivial explanation for the fact that the $\mathrm{pO}_{2}$-induced $\mathrm{DC}$ artifacts at adjacent electrodes can be negative and positive at the same time, which is related to the subdermal quasi-reference. A "true" reference electrode is an electrode with a thermodynamically precisely defined redox potential, i.e., its potential can be traced back to the potential of the standard hydrogen electrode. As usual in electrochemistry, the term "electrode" implies the electrode material and the electrolyte solution in which it is immersed. The calomel electrode $(\mathrm{Hg} / \mathrm{HgCl})$ or the $\mathrm{Ag} /$ $\mathrm{AgCl}$ electrode are examples of true reference electrodes whose potentials theoretically depend only on the chloride ion concentration of the surrounding electrolyte solution. In contrast, a metal (e.g., Pt) or metal oxide electrode (e.g., iridium dioxide) is a "quasi-reference" electrode. The potential of a quasi-reference is much less precisely defined than the potential of a true reference as it depends in a complex fashion on the electrolyte in which it is immersed. Thus, the potential of the Pt quasi-reference in the patients is floating depending on $\mathrm{pO}_{2}, \mathrm{pH}$, anion and cation species present, chemisorbing molecular species, etc., in the subdermal compartment. In other words, the potential of the subdermal Pt quasi-reference will change during a systemic hyperoxygenation episode as will the potential of the subdural Pt electrodes. In principle, the potential of all electrodes could change in the same direction, but by a slightly different amount in each case due to local inhomogeneities of the $\mathrm{pO}_{2}$ changes in the different compartments.
Depending on whether the local $\mathrm{pO}_{2}$ change at a given subdural electrode is larger or smaller than the local $\mathrm{pO}_{2}$ change at the subdermal quasi-reference, the measured potential change could then be either negative or positive.

In addition to $\mathrm{pO}_{2}$-induced $\mathrm{DC}$ artifacts, we also investigated $\mathrm{pH}$-induced $\mathrm{DC}$ artifacts of the Pt electrodes in our in vitro setup as extracellular $\mathrm{pH}$ changes are well known to occur in patients. For example, acidosis typically develops during brain ischemia [59, 60]. The $\mathrm{pH}$-induced DC artifacts were somewhat less dramatic than the $\mathrm{pO}_{2}$-induced $\mathrm{DC}$ artifacts, but they were still not negligible. The $\mathrm{pH}$-induced $\mathrm{DC}$ artifacts occur because $\mathrm{Pt}$ also adsorbs $\mathrm{H}^{+}$ions upon electron release $\left(\mathrm{H}_{\mathrm{ads}} \leftrightarrows \mathrm{H}^{+}+\mathrm{e}^{-}\right)$, which then may be released as $\mathrm{H}_{2}$ $\left(\mathrm{H}_{2} \leftrightarrows 2 \mathrm{H}_{\mathrm{ads}}\right)[61]$

Another interesting finding was that the lower the $\mathrm{pO}_{2}$, the less accurately the square voltage pulses were recorded by the $\mathrm{Pt}$ electrodes. Polarizable electrodes behave like a parallel-connected resistor and capacitor [38], with capacitance dominating the electrode behavior $[37,38]$. Although they reproduce high-frequency signals nearly perfectly, the amplitude of signals in the low-frequency DC range is distorted inversely proportional to the frequency. Depending on the electrical circuit, Pt electrodes may even return to the baseline during a square pulse stimulus [38]. Overall, our results further support the notion that the combined effects of $\mathrm{O}_{2}$ adsorption, surface roughening, and catalytic reactions at the Pt surface improve the electrode properties. This may be the reason why long-term recording in patients with subdural Pt electrodes is at all possible [40]. 
Limitations of our study include the relatively small number of patients and events, the retrospective design, and the fact that it was not precisely documented why intensivists and nurses had each increased $\mathrm{FiO}_{2}$. However, we would like to reiterate that brief episodes of hyperoxygenation before performing patient manipulations are a standard procedure routinely done in intensive care units around the world in a similar fashion.

\section{Conclusions}

If neurointensivists wish to use Pt electrodes to predict and detect ischemic conditions in the brain by monitoring SDs, the awareness of $\mathrm{pO}_{2}$ and $\mathrm{pH}$ interference with Pt electrodes is important because changes in $\mathrm{pO}_{2}$ and $\mathrm{pH}$ can produce large $\mathrm{DC}$ artifacts that should not be confused with SDs. Second, automatic algorithms for SD detection should be developed in such a way to reliably distinguish $\mathrm{pO}_{2}$-induced $\mathrm{DC}$ artifacts from SDs. Third, these interferences are one of the many reasons why it is more meaningful to perform monitoring of SDs with subdural Pt electrodes outside the brain parenchyma than with Pt electrodes located directly in the parenchyma $[36,40]$. SDs cause marked $\mathrm{p}_{\mathrm{ti}} \mathrm{O}_{2}$ changes in brain tissue during which $\mathrm{p}_{\mathrm{ti}} \mathrm{O}_{2}$ can either increase or decrease, depending on baseline cerebral blood flow, baseline $\mathrm{p}_{\mathrm{ti}} \mathrm{O}_{2}$, cerebral metabolic rate of $\mathrm{O}_{2}$, and hemodynamic responses to SDs [14, 43, 44, 50] (Figs. 1b, c, 2b). Moreover, SDs cause marked tissue acidosis $[59,60]$. If the Pt electrodes are located directly in the brain parenchyma [62], the DC signal consists not only of the field potential of SD but also of interference artifacts from $\mathrm{p}_{\mathrm{ti}} \mathrm{O}_{2}$ and tissue $\mathrm{pH}$ with the Pt electrodes, which greatly complicates interpretation. Hartings and colleagues previously found that monitoring only a single cortical location, as with an intraparenchymal depth array, may fail to capture $43 \%$ of SDs that occur in a broader area of subdural strip monitoring [40]. This already inadequate detection rate may be further worsened by signal cancellation if the Pt electrode is located directly in the brain parenchyma instead of subdurally and the negative DC shift of the SD is superimposed, for example, by a positive DC shift resulting from the SD-induced $\mathrm{p}_{\mathrm{ti}} \mathrm{O}_{2}$ response in the parenchyma and $\mathrm{O}_{2}$ interference with the Pt electrode. In contrast, if the Pt electrodes are located in the subdural space, the DC signal consists mainly of the field potential of SD because $\mathrm{O}_{2}$ tension and $\mathrm{pH}$ of the subdural space depends on perfusion of the capillaries of the meninges and not the capillaries of the brain. As SD is a gray matter phenomenon and not a meningeal phenomenon, the changes in meningeal blood flow, if any, are minor compared with the changes in cortical blood flow during SD. This means that the subdural space is generally a much more electrochemically stable compartment than the brain parenchyma. In addition, histological and immunohistochemical analyses of brain tissue surgically resected from patients with epilepsy suggested that depth electrodes cause upregulation of active inflammatory cell types and extravasation of plasma proteins, indicating significant local disruption of the blood-brain barrier, in an area that is 30 times the area of the physical insult [63]. Because the field potential changes of SDs in the subdural compartment are still large enough to be unambiguous [12, 14, 22, 23, 53, 54], in contrast with those in the epidural space or at the scalp surface $[18,64,65]$, our results provide further evidence that the subdural compartment is the ideal location for measuring SDs with $\mathrm{Pt}$ electrodes. Nevertheless, there are also arguments for the use of depth electrodes under certain circumstances. For a more comprehensive account of subdural versus depth electrodes we would like to refer to the COSBID recommendations on recording, analysis, and interpretation of SDs in neurointensive care [36]. Overall, the development of materials that are better than Pt should continue so that mechanically robust, nontoxic, nonpolarizable, noncatalytic electrodes with low impedance will be available for monitoring SDs in the future [66, 67].

\section{Supplementary Information}

The online version contains supplementary material available at https://doi. org/10.1007/s12028-021-01358-2.

\section{Author details \\ ${ }^{1}$ Center for Stroke Research Berlin, Campus Charité Mitte, Charité-Univer- sitätsmedizin Berlin, corporate member of Freie Universität Berlin, Humboldt- Universität zu Berlin, and Berlin Institute of Health, Charitéplatz 1, 10117 Berlin, Germany. ${ }^{2}$ Department of Experimental Neurology, Charité-Universitätsmedi- zin Berlin, corporate member of Freie Universität Berlin, Humboldt-Universität zu Berlin, and Berlin Institute of Health, Berlin, Germany. ${ }^{3}$ Department \\ of Neurology, Charité-Universitätsmedizin Berlin, corporate member of Freie Universität Berlin, Humboldt-Universität zu Berlin, and Berlin Institute of Health, Berlin, Germany. ${ }^{4}$ Fraunhofer Institute for Cell Therapy and Immu- nology-Branch Bioanalytics and Bioprocesses, Potsdam, Germany. ${ }^{5}$ Depart- ment of Neurosurgery, Evangelisches Krankenhaus Oldenburg, University of Oldenburg, Oldenburg, Germany. ${ }^{6}$ Bernstein Center for Computational Neuroscience Berlin, Berlin, Germany. ${ }^{7}$ Einstein Center for Neurosciences Berlin, Berlin, Germany.}

\section{Author Contributions}

SM: Study concept and design, data acquisition, analysis of data, and drafting of the article. NGE: Critical revision of the article. JW: Data acquisition, critical revision of the article. JPD: Study concept and design, data acquisition, analysis of data, drafting of the article. The final manuscript was approved by all authors.

\section{Source of Support}

Open Access funding enabled and organized by Projekt DEAL. This work was supported by grants from the: DFG Deutsche Forschungsgemeinschaft (German Research Council) (DFG DR 323/5-1) to JW and JPD, DFG DR 323/10-1 to JPD and BMBF Bundesministerium fuer Bildung und Forschung (Era-Net Neuron EBio2, with funds from BMBF 01EW2004) to JPD.

\section{Conflicts of interest}

There are no competing interests. 


\section{Ethical Approval/Informed Consent}

All ethical guidelines have been adhered to as explained in the "Methods" section.

\section{Open Access}

This article is licensed under a Creative Commons Attribution 4.0 International License, which permits use, sharing, adaptation, distribution and reproduction in any medium or format, as long as you give appropriate credit to the original author(s) and the source, provide a link to the Creative Commons licence, and indicate if changes were made. The images or other third party material in this article are included in the article's Creative Commons licence, unless indicated otherwise in a credit line to the material. If material is not included in the article's Creative Commons licence and your intended use is not permitted by statutory regulation or exceeds the permitted use, you will need to obtain permission directly from the copyright holder. To view a copy of this licence, visit http://creativecommons.org/licenses/by/4.0/.

\section{Publisher's Note}

Springer Nature remains neutral with regard to jurisdictional claims in published maps and institutional affiliations.

Received: 6 June 2021 Accepted: 15 September 2021 Published online: 7 October 2021

\section{References}

1. Dreier JP, Lemale CL, Kola V, Friedman A, Schoknecht K. Spreading depolarization is not an epiphenomenon but the principal mechanism of the cytotoxic edema in various gray matter structures of the brain during stroke. Neuropharmacology. 2018;134(Pt B):189-207.

2. Kirov SA, Fomitcheva IV, Sword J. Rapid neuronal ultrastructure disruption and recovery during spreading depolarization-induced cytotoxic edema. Cereb Cortex. 2020;30(10):5517-31.

3. Cain SM, Bohnet B, LeDue J, et al. In vivo imaging reveals that pregabalin inhibits cortical spreading depression and propagation to subcortical brain structures. Proc Natl Acad Sci USA. 2017;114(9):2401-6.

4. Busch E, Gyngell ML, Eis M, Hoehn-Berlage M, Hossmann KA. Potassiuminduced cortical spreading depressions during focal cerebral ischemia in rats: contribution to lesion growth assessed by diffusion-weighted NMR and biochemical imaging. J Cereb Blood Flow Metab. 1996;16(6):1090-9.

5. Takano K, Latour LL, Formato JE, et al. The role of spreading depression in focal ischemia evaluated by diffusion mapping. Ann Neurol. 1996:39(3):308-18.

6. Major S, Huo S, Lemale CL, et al. Direct electrophysiological evidence that spreading depolarization-induced spreading depression is the pathophysiological correlate of the migraine aura and a review of the spreading depolarization continuum of acute neuronal mass injury. Geroscience. 2020;42(1):57-80.

7. Olesen J, Larsen B, Lauritzen M. Focal hyperemia followed by spreading oligemia and impaired activation of rCBF in classic migraine. Ann Neurol. 1981;9(4):344-52.

8. Woitzik J, Hecht N, Pinczolits A, et al. Propagation of cortical spreading depolarization in the human cortex after malignant stroke. Neurology. 2013:80(12):1095-102.

9. Dohmen C, Sakowitz OW, Fabricius M, et al. Spreading depolarizations occur in human ischemic stroke with high incidence. Ann Neurol. 2008;63(6):720-8.

10. Hartings JA, Andaluz N, Bullock MR, et al. Prognostic value of spreading depolarizations in patients with severe traumatic brain injury. JAMA Neurol. 2020;77(4):489-99.

11. Fabricius M, Fuhr S, Bhatia R, et al. Cortical spreading depression and periinfarct depolarization in acutely injured human cerebral cortex. Brain. 2006;129(Pt 3):778-90.

12. Luckl J, Lemale CL, Kola V, et al. The negative ultraslow potential, electrophysiological correlate of infarction in the human cortex. Brain. 2018;141(6):1734-52.
13. Dreier JP, Woitzik J, Fabricius M, et al. Delayed ischaemic neurological deficits after subarachnoid haemorrhage are associated with clusters of spreading depolarizations. Brain. 2006;129(Pt 12):3224-37.

14. Dreier JP, Major S, Manning A, et al. Cortical spreading ischaemia is a novel process involved in ischaemic damage in patients with aneurysmal subarachnoid haemorrhage. Brain. 2009;132(Pt 7):1866-81.

15. Helbok R, Schiefecker AJ, Friberg C, et al. Spreading depolarizations in patients with spontaneous intracerebral hemorrhage: Association with perihematomal edema progression. J Cereb Blood Flow Metab. 2017;37(5):1871-82.

16. Mohammad LM, Abbas M, Shuttleworth CW, et al. Spreading depolarization may represent a novel mechanism for delayed fluctuating neurological deficit after chronic subdural hematoma evacuation. J Neurosurg. 2020;134:1294-302.

17. Carlson AP, Shuttleworth CW, Major S, et al. Terminal spreading depolarizations causing electrocortical silencing prior to clinical brain death: case report. J Neurosurg. 2019;131(6):1773-9.

18. Dreier JP, Major S, Lemale $\mathrm{CL}$, et al. Correlates of spreading depolarization, spreading depression, and negative ultraslow potential in epidural versus subdural electrocorticography. Front Neurosci. 2019;13:373.

19. Dreier JP, Major S, Foreman B, et al. Terminal spreading depolarization and electrical silence in death of human cerebral cortex. Ann Neurol. 2018;83(2):295-310.

20. Dreier JP, Reiffurth C. The stroke-migraine depolarization continuum. Neuron. 2015;86(4):902-22.

21. Hartings JA, Shuttleworth CW, Kirov SA, et al. The continuum of spreading depolarizations in acute cortical lesion development: examining Leao's legacy. J Cereb Blood Flow Metab. 2017;37(5):1571-94.

22. Oliveira-Ferreira Al, Milakara D, Alam M, et al. Experimental and preliminary clinical evidence of an ischemic zone with prolonged negative DC shifts surrounded by a normally perfused tissue belt with persistent electrocorticographic depression. J Cereb Blood Flow Metab. 2010;30(8):1504-19.

23. Hartings JA, York J, Carroll CP, et al. Subarachnoid blood acutely induces spreading depolarizations and early cortical infarction. Brain. 2017; 140(10):2673-90.

24. Dreier JP. The role of spreading depression, spreading depolarization and spreading ischemia in neurological disease. Nat Med. 2011;17(4):439-47.

25. Leão AAP. Further observations on the spreading depression of activity in the cerebral cortex. J Neurophysiol. 1947;10(6):409-14.

26. Revankar GS, Winkler MKL, Major S, et al. Spreading depolarizations and seizures in clinical subdural electrocorticographic recordings. In: Varelas PN, Claassen J, editors., et al., Seizures in critical care. A guide to diagnosis and therapeutics. New York: Springer; 2017. p. 77-90

27. Fabricius M, Fuhr S, Willumsen $L$, et al. Association of seizures with cortical spreading depression and peri-infarct depolarisations in the acutely injured human brain. Clin Neurophysiol. 2008;119(9):1973-84.

28. Dreier JP, Major S, Pannek HW, et al. Spreading convulsions, spreading depolarization and epileptogenesis in human cerebral cortex. Brain. 2012;135(Pt 1):259-75.

29. Maslarova A, Alam M, Reiffurth C, et al. Chronically epileptic human and rat neocortex display a similar resistance against spreading depolarization in vitro. Stroke. 2011:42(10):2917-22.

30. Jansen NA, Dehghani A, Linssen MML, et al. First FHM3 mouse model shows spontaneous cortical spreading depolarizations. Ann Clin Transl Neurol. 2020;7(1):132-8.

31. Tomkins $\mathrm{O}$, Friedman $\mathrm{O}$, Ivens $\mathrm{S}$, et al. Blood-brain barrier disruption results in delayed functional and structural alterations in the rat neocortex. Neurobiol Dis. 2007;25(2):367-77.

32. Claes L, Del-Favero J, Ceulemans B, et al. De novo mutations in the sodium-channel gene SCN1A cause severe myoclonic epilepsy of infancy. Am J Hum Genet. 2001;68(6):1327-32.

33. Escayg A, MacDonald BT, Meisler MH, et al. Mutations of SCN1A, encoding a neuronal sodium channel, in two families with GEFS+2. Nat Genet. 2000;24(4):343-5

34. Lauritzen $M$, Dreier JP, Fabricius $M$, et al. Clinical relevance of cortical spreading depression in neurological disorders: migraine, malignant 
stroke, subarachnoid and intracranial hemorrhage, and traumatic brain injury. J Cereb Blood Flow Metab. 2011;31(1):17-35.

35. Lesser RP, Crone NE, Webber WRS. Subdural electrodes. Clin Neurophysiol. 2010;121(9):1376-92.

36. Dreier JP, Fabricius M, Ayata C, et al. Recording, analysis, and interpretation of spreading depolarizations in neurointensive care: review and recommendations of the COSBID research group. J Cereb Blood Flow Metab. 2017;37(5):1595-625

37. Tallgren P, Vanhatalo S, Kaila K, Voipio J. Evaluation of commercially available electrodes and gels for recording of slow EEG potentials. Clin Neurophysiol. 2005;116(4):799-806.

38. Grimnes S, Martinsen ØG. Chapter 7—Electrodes. In: Grimnes S, Martinsen $\varnothing \mathrm{G}$, editors. Bioimpedance and bioelectricity basics (third edition). Oxford: Academic Press; 2015. p. 179-254.

39. Li C, Narayan RK, Wu PM, et al. Evaluation of microelectrode materials for direct-current electrocorticography. J Neural Eng. 2016;13(1):016008.

40. Hartings JA, Li C, Hinzman JM, et al. Direct current electrocorticography for clinical neuromonitoring of spreading depolarizations. J Cereb Blood Flow Metab. 2017;37(5):1857-70.

41. Jewell S, Hobson S, Brewer G, et al. Development and evaluation of a method for automated detection of spreading depolarizations in the injured human brain. Neurocrit Care. 2021. https://doi.org/10.1007/ s12028-021-01228-x.

42. von Bornstadt D, Houben T, Seidel JL, et al. Supply-demand mismatch transients in susceptible peri-infarct hot zones explain the origins of spreading injury depolarizations. Neuron. 2015;85(5):1117-31.

43. Winkler MK, Dengler N, Hecht N, et al. Oxygen availability and spreading depolarizations provide complementary prognostic information in neuromonitoring of aneurysmal subarachnoid hemorrhage patients. J Cereb Blood Flow Metab. 2017;37(5):1841-56.

44. Bosche B, Graf R, Ernestus Rl, et al. Recurrent spreading depolarizations after subarachnoid hemorrhage decreases oxygen availability in human cerebral cortex. Ann Neurol. 2010;67(5):607-17.

45. Burr HS, Harmann PJJ. Voltage gradients in the nervous system. Trans Amer Neurol Ass. 1939;65:11-4.

46. Goldring S, Ulett G, O'Leary J, Greditzer A. Initial survey of slow potential changes obtained under resting conditions and incident to convulsive therapy. Electroencephalogr Clin Neurophysiol. 1950;2(3):297-308.

47. Goldensohn ES, Schoenfeld RL, Hoefer PF. The slowly changing voltage of the brain and the electrocorticogram. Electroencephalogr Clin Neurophysiol. 1951;3(2):231-6.

48. Kempinsky WH. Steady potential gradients in experimental cerebral vascular occlusion. Electroencephalogr Clin Neurophysiol. 1954;6(3):375-88.

49. Goldring $\mathrm{S}, \mathrm{O}$ 'Leary JL. Experimentally derived correlates between ECG and steady cortical potential. J Neurophysiol. 1951;14(4):275-88.

50. Hinzman JM, Andaluz N, Shutter LA, et al. Inverse neurovascular coupling to cortical spreading depolarizations in severe brain trauma. Brain. 2014;137(Pt 11):2960-72.

51. Dreier JP, Korner K, Ebert N, et al. Nitric oxide scavenging by hemoglobin or nitric oxide synthase inhibition by N-nitro-L-arginine induces cortical spreading ischemia when $\mathrm{K}+$ is increased in the subarachnoid space. J Cereb Blood Flow Metab. 1998;18(9):978-90.

52. Dreier JP, Kleeberg J, Alam M, et al. Endothelin-1-induced spreading depression in rats is associated with a microarea of selective neuronal necrosis. Exp Biol Med (Maywood). 2007;232(2):204-13.

53. Milakara D, Grozea C, Dahlem M, et al. Simulation of spreading depolarization trajectories in cerebral cortex: correlation of velocity and susceptibility in patients with aneurysmal subarachnoid hemorrhage. Neuroimage Clin. 2017;16:524-38.

54. Hartings JA, Watanabe T, Bullock MR, et al. Spreading depolarizations have prolonged direct current shifts and are associated with poor outcome in brain trauma. Brain. 2011;134:1529-40.
55. Gomez-Marin AM, Feliu JM, Ticianelli E. Oxygen reduction on platinum surfaces in acid media: experimental evidence of a CECE/DISP initial reaction path. ACS Catal. 2019;9(3):2238-51.

56. Rinaldo SG, Lee W, Stumper J, Eikerling M. Mechanistic principles of platinum oxide formation and reduction. Electrocatalysis. 2014;5(3):262-72.

57. van Spronsen MA, Frenken JWM, Groot IMN. Observing the oxidation of platinum. Nat Commun. 2017:8(1):429.

58. Montemore MM, van Spronsen MA, Madix RJ, Friend CM. O2 Activation by metal surfaces: implications for bonding and reactivity on heterogeneous catalysts. Chem Rev. 2018;118(5):2816-62.

59. Mutch WA, Hansen AJ. Extracellular pH changes during spreading depression and cerebral ischemia: mechanisms of brain $\mathrm{pH}$ regulation. $J$ Cereb Blood Flow Metab. 1984;4(1):17-27.

60. Windmuller $\mathrm{O}$, Lindauer $\mathrm{U}$, Foddis $\mathrm{M}$, et al. lon changes in spreading ischaemia induce rat middle cerebral artery constriction in the absence of NO. Brain. 2005;128(Pt 9):2042-51.

61. Durst J, Siebel A, Simon C, et al. New insights into the electrochemical hydrogen oxidation and evolution reaction mechanism. Energy Environ Sci. 2014;7(7):2255-60.

62. Jeffcote T, Hinzman JM, Jewell SL, et al. Detection of spreading depolarization with intraparenchymal electrodes in the injured human brain. Neurocrit Care. 2014;20(1):21-31.

63. Liu JY, Thom M, Catarino CB, et al. Neuropathology of the blood-brain barrier and pharmaco-resistance in human epilepsy. Brain. 2012;135(Pt 10):3115-33.

64. Drenckhahn C, Winkler MK, Major S, et al. Correlates of spreading depolarization in human scalp electroencephalography. Brain. 2012;135(Pt 3):853-68.

65. Hartings JA, Wilson JA, Hinzman JM, et al. Spreading depression in continuous electroencephalography of brain trauma. Ann Neurol. 2014;76(5):681-94

66. Masvidal-Codina E, Illa X, Dasilva M, et al. High-resolution mapping of infraslow cortical brain activity enabled by graphene microtransistors. Nat Mater. 2018;18:280-8.

67. Hartings JA. How slow can you go? Nat Mater. 2019;18(3):194-6.

68. Wolf S, Horn P, Frenzel C, et al. Comparison of a new brain tissue oxygenation probe with the established standard. Acta Neurochir Suppl. 2012;114:161-4.

69. Ohkuma H, Manabe H, Tanaka M, Suzuki S. Impact of cerebral microcirculatory changes on cerebral blood flow during cerebral vasospasm after aneurysmal subarachnoid hemorrhage. Stroke. 2000;31(7):1621-7.

70. Ndubuizu O, LaManna JC. Brain tissue oxygen concentration measurements. Antioxid Redox Signal. 2007;9(8):1207-19.

71. Piilgaard $\mathrm{H}$, Lauritzen M. Persistent increase in oxygen consumption and impaired neurovascular coupling after spreading depression in rat neocortex. J Cereb Blood Flow Metab. 2009;29(9):1517-27.

72. Takano T, Tian GF, Peng W, et al. Cortical spreading depression causes and coincides with tissue hypoxia. Nat Neurosci. 2007;10(6):754-62.

73. Lauritzen M. Pathophysiology of the migraine aura. The spreading depression theory. Brain. 1994;117(Pt 1):199-210.

74. Dreier JP, Ebert N, Priller J, et al. Products of hemolysis in the subarachnoid space inducing spreading ischemia in the cortex and focal necrosis in rats: a model for delayed ischemic neurological deficits after subarachnoid hemorrhage? J Neurosurg. 2000;93(4):658-66.

75. Frontera JA, Claassen J, Schmidt JM, et al. Prediction of symptomatic vasospasm after subarachnoid hemorrhage: the modified fisher scale. Neurosurgery. 2006;59(1):21-7 (discussion -7). 